\title{
Structural and Optical Properties of ZnO Nanowires Doped with Magnesium
}

\author{
H. Zhuang* , J. Wang, H. Liu, J. Li And P. Xu \\ Institutions of Semiconductors, Shandong Normal University, Jinan 250014, P.R. China
}

(Received June 13, 2010; revised version October 25, 2010; in final form December 9, 2010)

\begin{abstract}
$\mathrm{ZnO}$ nanowires doped with $\mathrm{Mg}$ have been successfully prepared on Au-coated $\mathrm{Si}$ (111) substrates using chemical vapor deposition method with a mixture of $\mathrm{ZnO}, \mathrm{Mg}$, and activated carbon powders as reactants at $850^{\circ} \mathrm{C}$. The structural, compositional, morphological and optical properties of the samples were characterized by X-ray diffraction, scanning electron microscopy, transmission electron microscopy, high-resolution transmission electron microscopy, and photoluminescence spectroscopy. The nanowires are single crystalline in nature and preferentially grow up along [0001] direction with the average diameter and length of about $60 \mathrm{~nm}$ and several hundred micrometers, respectively, thinner and longer than the results of literature using the similar method. Room temperature photoluminescence spectroscopy shows a blueshift from the bulk band gap emission, which can be attributed to $\mathrm{Mg}$ doping that were detected by energy dispersive X-ray analysis EDX in the nanowires. Finally, the possible growth mechanism of crystalline ZnO nanowires is discussed briefly.
\end{abstract}

PACS: $61.46 . \mathrm{Km}, 61.72 . u j, 81.15 . \mathrm{Gh}, 78.67 .-\mathrm{n}$

\section{Introduction}

Semiconductor nanostructures have been considered as promising components for future electronics, photonics, biosensing and nanodevices [1]. At room temperature, with a wide band gap of $3.37 \mathrm{eV}$ and large exciton binding energy of $60 \mathrm{meV}, \mathrm{ZnO}$ has been recognized as one of the most important semiconductor materials in scientific research and technological applications [2]. To date, various $\mathrm{ZnO}$ nanostructures have been successfully synthesized, including nanorods, nanotubes, nanowires, nanobelt, and nanobridge [3]. A key requirement for many applications involving $\mathrm{ZnO}$ is its doping with special elements in order to improve its electrical and optical properties [4], and the doping effect has attracted extraordinary attention.

Recently, various doped $\mathrm{ZnO}$ nanostructures with different elements (e.g., $\mathrm{Al}, \mathrm{Ga}, \mathrm{In}, \mathrm{Sn}, \mathrm{Co}$ and $\mathrm{Sb}$ ) have been achieved [5-11]. Alloying $\mathrm{ZnO}$ with $\mathrm{Mg}$ was shown to realize the control of the band gap for the realization of light-emitting devices operating in a wider wavelength region [12] without affecting lattice constant, because ionic radius of $\mathrm{Mg}(0.57 \AA)$ and $\mathrm{Zn}(0.60 \AA)$ are almost similar [13], the Zn positions can be easily substituted by $\mathrm{Mg}$ under certain conditions.

By far, $\mathrm{Mg}$-doped $\mathrm{ZnO}$ nanostructures have been successfully fabricated by a lot of methods, such as

\footnotetext{
* corresponding author; e-mail: zhuanghuizhao@sdnu.edu.cn
}

nanowires, nanowire arrays and $\mathrm{ZnO} / \mathrm{MgZnO}$ quantum wells by pulsed laser deposition (PLD) [14-16], nanopillars and nanorods by metal-organic chemical vapor deposition (MOCVD) [17, 18], nanorods, nanowires, ternary nanowires, nanoterapods, nanopagodas and dendritic $\mathrm{Zn}_{1-x} \mathrm{Mg}_{x} \mathrm{O}$ nanostructures by thermal evaporation [14, 19-23], nanowires by thermal diffusion [24]. Nevertheless, there are only a few reports on Mg-doped $\mathrm{ZnO}$ nanowires using a mixture of $\mathrm{ZnO}$ and activated carbon powders as source materials reported yet except for Wei et al. [25]. Carbothermal reduction, as a simple and effective method, has been utilized widely. The major advantage of this method should lie in its ability to decrease the temperature from $1975 \mathrm{~K}$ (which is essential for $\mathrm{ZnO}$ powder to melt) to lower than $1000 \mathrm{~K}$ : more specifically, its advantage is in its potential for industrial production. This method can possibly be extended to preparation of many other semiconductor nanowires, such as $\operatorname{In}_{2} \mathrm{O}_{3}[26]$, $\mathrm{SiC}$ [27], $\mathrm{SiO}_{2}$ [28], $\mathrm{Si}_{3} \mathrm{~N}_{4}$ [29], etc.

In this paper, we reported that high-quality Mg-doped $\mathrm{ZnO}$ nanowires were synthesized on $\mathrm{Si}$ (111) substrate by CVD method with a mixture of $\mathrm{ZnO}, \mathrm{Mg}$, and activated carbon powders as reactants on Au-coated $\mathrm{Si}$ (111) substrates at the temperature of $850^{\circ} \mathrm{C}$ under Ar atmosphere. This growth method allows a continuous synthesis and the process is simple and inexpensive, suitable for commercial scale production. The morphology, crystallinity and optical properties of $\mathrm{Mg}$ doped $\mathrm{ZnO}$ nanowires were carefully investigated. The average length of the nanowires in our experiment is up to 
several hundreds of micrometers, which is much longer than result given by Ref. [25], and the average diameter is smaller. Finally, the growth mechanism is briefly discussed.

\section{Experimental details}

In our experiment, the preparation process of $\mathrm{Mg}$ -doped $\mathrm{ZnO}$ nanowires could be fallen into two steps in the whole process.

The first step was that a thin layer of $\mathrm{Au}$ films was deposited on Si substrates by sputtering Au target in JCK-500A RF magnetron sputtering system. Si (111) substrates were cleaned by sonicating in toluene, acetone, ethanol, and deionized water for $30 \mathrm{~min}$ in sequence. The conditions of sputtering process were as follows: the distance between the substrates and the target was $80 \mathrm{~mm}$; the background pressure was $7 \times 10^{-4} \mathrm{~Pa}$; the working gas was pure $\operatorname{Ar}(\geq 99.99 \%)$ and the working pressure was $2 \mathrm{~Pa}$; the output voltage and output current of the radio frequency generator were $320 \mathrm{~V}$ and $50 \mathrm{~mA}$, respectively; the $\mathrm{Au}$ sputtering time was $2 \mathrm{~s}$ and the thickness of resulting Au thin film was equal to about $12 \mathrm{~nm}$.

The second step was that the Mg-doped $\mathrm{ZnO}$ nanowires were synthesized by a chemical vapor deposition (CVD) process, which was done in a conventional horizontal tube furnace (L4513II-2/QWZ). A mixture of $\mathrm{ZnO}$ (purity 99.9\%), $\mathrm{Mg}$ (purity 99.99\%) and graphite powders with the mass ratio of $7: 2: 0.1$ was used as the source materials. Both the source materials and the Au-coated Si substrates were placed at a quartz boat with a distance of $2 \mathrm{~cm}$ between them. After heating the furnace to $850{ }^{\circ} \mathrm{C}$ at a rate of $50-100{ }^{\circ} \mathrm{C} / \mathrm{min}$, the flowing $\operatorname{Ar}(99.999 \%)$ gas was introduced into the tube to flush out the residual air at a flow rate of $500 \mathrm{sccm}$ for $5 \mathrm{~min}$. Then the quartz boat loaded with the Si substrates and source materials was quickly inserted into it. The source materials were positioned at the centre of the furnace, and the Si substrates were located downstream of the gas flow to collect products. The temperature was held for 10 min under a constant Ar flow of $150 \mathrm{sccm}$. Finally, the boat was pulled out and cooled to room temperature under atmosphere, and white cotton-like products appeared on the substrates. In addition, under the same condition except the lack of $\mathrm{Mg}$ in the source materials, we have prepared pure $\mathrm{ZnO}$ nanowires and have used them for the comparison when taking PL spectra.

The morphology and surface microstructure of the samples were characterized by a Hitachi S-570 scanning electron microscopy (SEM), a Hitachi H-800 transmission electron microscopy (TEM) and a Philips Tecnai-20 high resolution transmission electron microscope (HRTEM). The microstructure and chemical composition of the samples were investigated by a Rigaku $\mathrm{D} /$ max-rB X-ray diffraction $(\mathrm{XRD})$ meter with a $\mathrm{Cu} K_{\alpha}$ line and an energy dispersive X-ray energy spectroscopy (EDX) system. The room temperature photoluminescence (PL) spectrum of the products was measured by a FLS920 fluorescence spectrophotometer with a $\mathrm{He}-\mathrm{Cd}$ laser as the excitation light source at $325 \mathrm{~nm}$.

\section{Results and disscussion}

\subsection{Microstructure analysis}

Figure 1 shows the typical XRD pattern of the samples. As seen from Fig. 1, all the diffraction peaks in the pattern can be easily assigned to hexagonal wurtzite $\mathrm{ZnO}$, which are in agreement with the reported standard values (JCPDS No. 36-1451). The (002) diffraction peak at $2 \theta=34.58^{\circ}$ has a slight shift from the standard for bulk $\mathrm{ZnO}\left(34.40^{\circ}\right)[30]$, indicating that $\mathrm{Mg}^{2+}$ has incorporated into the $\mathrm{ZnO}$ host lattice and substitutes for $\mathrm{Zn}^{2+}$, as the ionic radius of $\mathrm{Mg}^{2+}(0.057 \mathrm{~nm})$ is smaller than $\mathrm{Zn}^{2+}$ (with an ionic radius $0.060 \mathrm{~nm}$ ). No diffraction peaks from metallic $\mathrm{Zn}$ and $\mathrm{Mg}$ or other phase have been found, revealing that $\mathrm{Mg}$ doping has not changed the wurtzite structure of $\mathrm{ZnO}$ because of its small content, which is also compatible with results from the substitution of $\mathrm{Mg}$ for $\mathrm{Zn}$ site and previous reports [22]. In addition, the sharp diffraction peaks reveal that the $\mathrm{ZnO}$ nanowires possess good crystalline quality. Au diffraction peaks are not detected by XRD, due to the small size of Au particles (about $3 \mathrm{~nm}$ ).

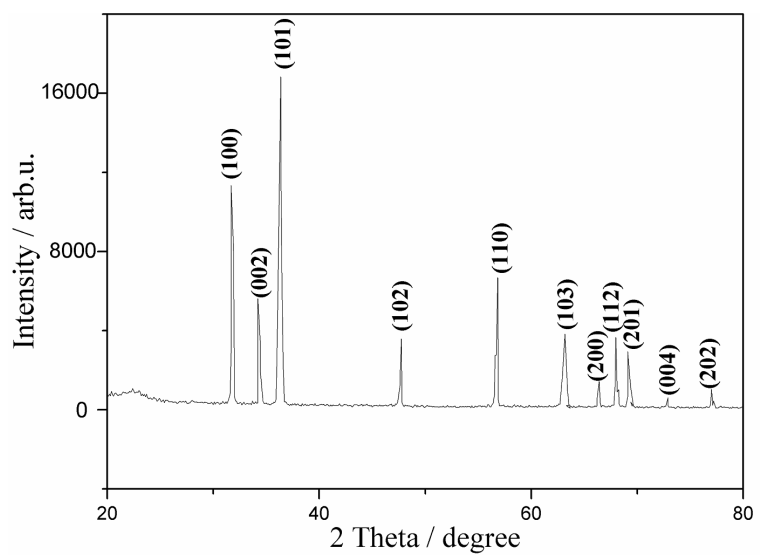

Fig. 1. XRD pattern of Mg-doped $\mathrm{ZnO}$ nanowires with a hexagonal wurtzite structure.

\subsection{Surface morphology}

Surface morphology of the samples and nanowires dimensions were determined by SEM. Figure 2 shows the typical SEM images of the as-synthesized samples at different magnifications. Figure 2a depicts that the morphology of the nanostructures consists of high-density $\mathrm{ZnO}$ nanowires. These nanowires interwine with each other and distribute on the whole substrate surface randomly. A magnified SEM image (Fig. 2b) shows that the typical diameter and length are about $60 \mathrm{~nm}$ and several hundred micrometers, respectively. In addition, no metal particle is observed at the tops of the nanowires. 

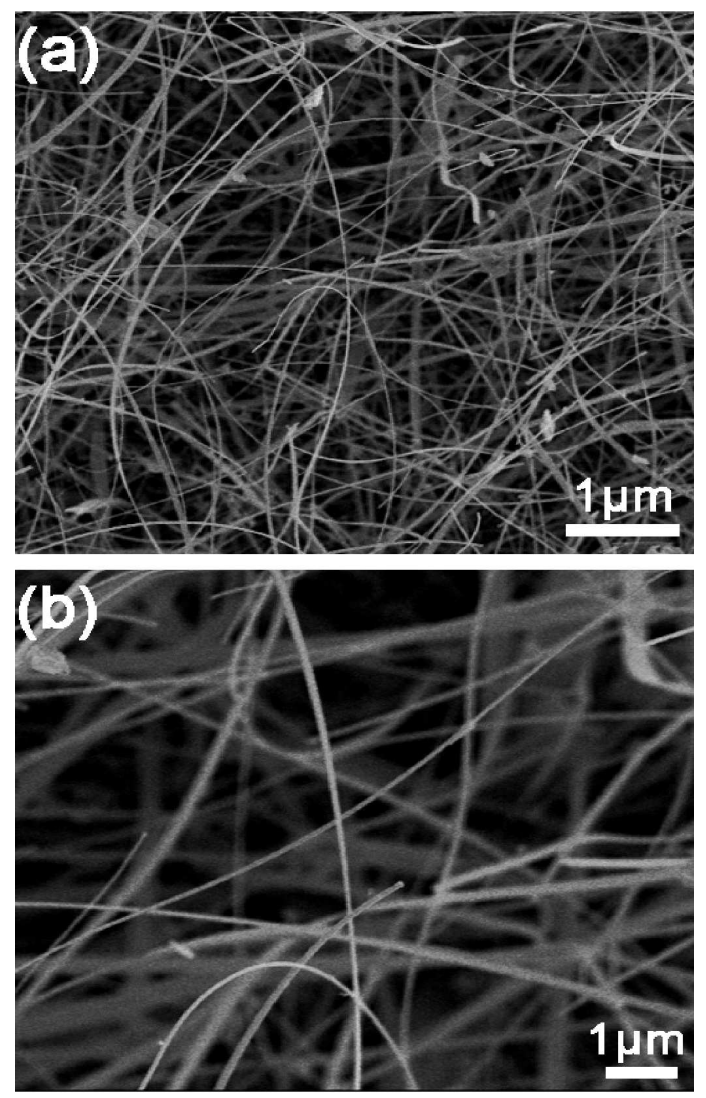

Fig. 2. Typical SEM images of the Mg-doped $\mathrm{ZnO}$ nanowires at different magnifications.

For better understanding of the morphology properties, TEM, HRTEM and selected area electron diffraction (SAED) pattern were employed to further investigate the as-synthesized $\mathrm{ZnO}$ nanostructures, as shown in Fig. 3a,b.

As shown in Fig. 3a, TEM image of a single $\mathrm{ZnO}$ nanowire reveals that the $\mathrm{ZnO}$ nanowire has a diameter of about $60 \mathrm{~nm}$, and its surface is coarse, which may be attributed to the defects from $\mathrm{Mg}$ doping during growth. The inset of Fig. 3a shows the selected area electron diffraction (SAED) pattern of the Mg-doped $\mathrm{ZnO}$ nanowires, which demonstrates that the nanowires have a high crystal quality due to the regular electron diffraction pattern. The SAED pattern is consistent with the hexagonal wurtzite structure of $\mathrm{ZnO}$ with no second phase detected. Therefore, we can conclude that the Mg doping did not perturb significantly the lattice structure of the $\mathrm{ZnO}$ matrix.

Figure $3 \mathrm{~b}$ shows the HRTEM lattice image of the single $\mathrm{Mg}$-doped $\mathrm{ZnO}$ nanowire, the visible lattice fringes disclose that the nanowire is high quality hexagonal wurtzite single crystalline grown along [0001] direction. The lattice spacing between the two (0002) fringes is $0.258 \mathrm{~nm}$, which is slightly smaller than the plane distance $(0.260 \mathrm{~nm})$ of undoped $\mathrm{ZnO}$ (0002). This finding can be explained as the result of a random distribution
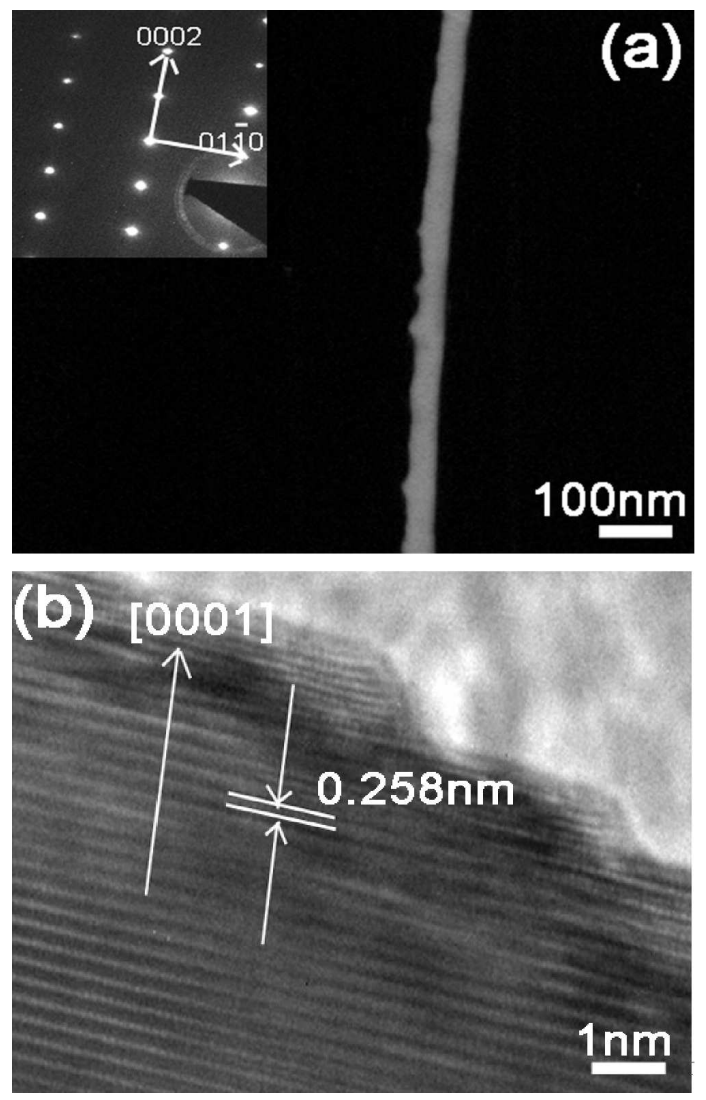

Fig. 3. (a) TEM image of single Mg-doped $\mathrm{ZnO}$ nanowire and the correspoding SAED pattern, (b) HRTEM image of the nanowire.

of $\mathrm{Mg}$ ions replacing $\mathrm{Zn}$ in the $\mathrm{ZnO}$ crystal lattice. This confirms that introduction of divalent $\mathrm{Mg}^{2+}$ in the $\mathrm{ZnO}$ lattice did not affect the growth direction.

\subsection{Chemical composition analysis}

Corresponding chemical composition of the synthesized $\mathrm{ZnO}$ nanowires were determined by EDX spectroscopy. Figure 4 shows a typical EDX spectrum of the edge of the nanowires. It is clear that only the $\mathrm{Zn}$,

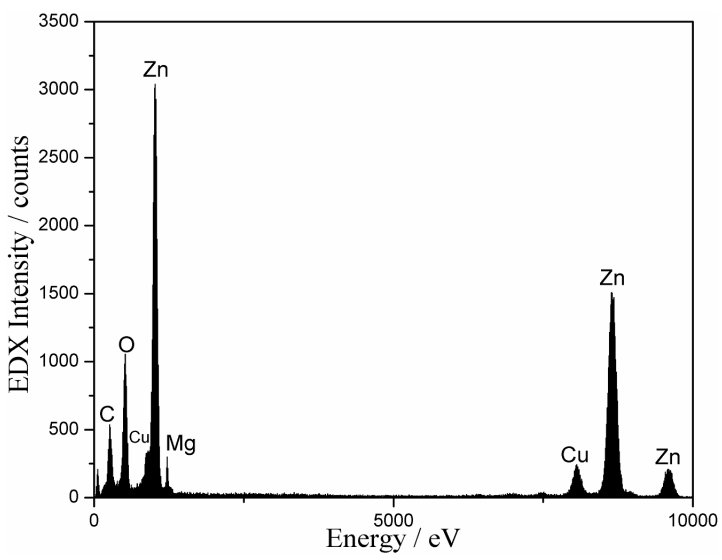

Fig. 4. EDX spectrum of the single nanowire. 
$\mathrm{Mg}, \mathrm{C}, \mathrm{Cu}$ and $\mathrm{O}$ peaks are observed (the $\mathrm{Cu}$ peak comes from the TEM sample grid and the $\mathrm{C}$ peak comes mainly from atmospheric contamination due to the exposure of the sample to air [31]), confirming that the compositions of the products are Mg-doped $\mathrm{ZnO}$ without impurity. Similar results were obtained from different areas of the nanowires for several times.

\subsection{Optical properties}

Figure 5 shows the room temperature PL spectrum with $\mathrm{He}-\mathrm{Cd}$ laser excitation at $325 \mathrm{~nm}$. Both the $\mathrm{Mg}$ -doped and undoped samples show two emission bands: a narrow UV emission and a broad green emission. The UV emission is commonly originated from the free-exitonic recombination through an exciton-exciton collision process corresponding to the near band-edge emission of band gap $\mathrm{ZnO}$ [3]. Compared with the undoped one, the UV peak of the doped sample shifts to $378 \mathrm{~nm}$ from $383 \mathrm{~nm}$. The peak at $378 \mathrm{~nm}$ and $383 \mathrm{~nm}$ corresponding to $E_{v}=3.28 \mathrm{eV}$ and $3.24 \mathrm{eV}$, respectively, indicating that the band-gap energy has increased by the doping of $\mathrm{Mg}$ in the nanowire, because $\mathrm{MgO}(7.7 \mathrm{eV})$ has a wider band-gap than $\mathrm{ZnO}(3.37 \mathrm{eV})$ [32], in agreement with the XRD and EDX results. It is worthy to note that this blueshift is not associated by quantum confinement effects, because the average diameter of the nanowires is about $60 \mathrm{~nm}$, far larger than the exciton Bohr radius $(\approx 1.8-2.0 \mathrm{~nm})$ [33] of $\mathrm{ZnO}$. The green emission is generally considered to be related to various intrinsic defects produced during $\mathrm{ZnO}$ preparation, but the exact mechanism is still unclear [34]. The presence of oxygen vacancies $\left(\mathrm{V}_{\mathrm{O}}\right)$, zinc vacancies $\left(\mathrm{V}_{\mathrm{Zn}}\right)$, interstitial zinc $\left(\mathrm{Zn}_{\mathrm{i}}\right)$ and antisite defects $\left(\mathrm{O}_{\mathrm{Zn}}\right)$ have been attributed to correspond to the green emission of $\mathrm{ZnO}$ by different researchers [35-37]. In our experiment, an interesting phenomenon is that the green band in the Mg-doped $\mathrm{ZnO}$ is much stronger than that of undoped $\mathrm{ZnO}$. This may be attributed to surface-recombination effect on the thin-nanowires system [38]. Of course, the detailed explanation of PL will be given elsewhere.

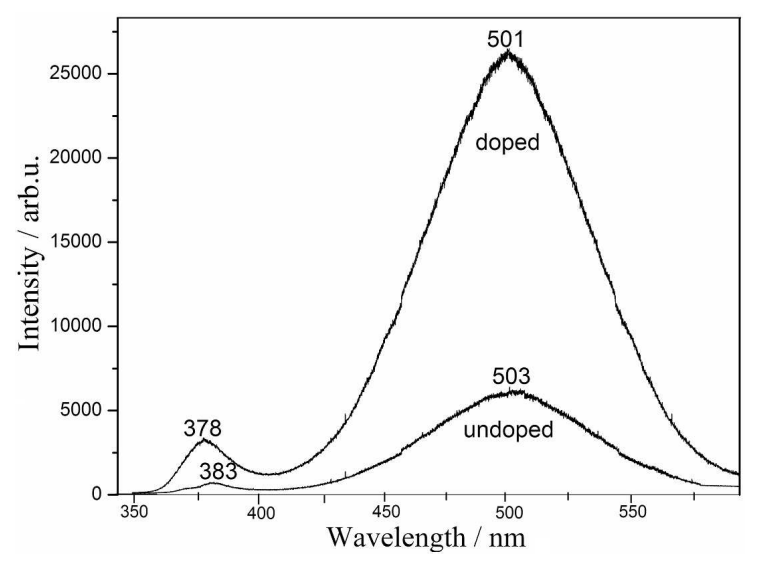

Fig. 5. Room temperature PL spetcrum of undoped and $\mathrm{Mg}$-doped $\mathrm{ZnO}$ samples.

\subsection{Growth mechanism}

Vapor-liquid-solid (VLS) and vapor-solid (VS) mechanisms have been proposed to explain the formation of $\mathrm{ZnO}$ nanostructures. The VLS process begins from the absorption of the source materials from the gas phase into the metal liquid droplets and forms the liquid alloy. When this liquid alloy becomes saturated, a solid precipitate is formed which serves as a preferred site for further deposition. The dominant characteristic of the VLS mechanism is that a metal particle is located at the growth front of the nanowires and acts as the catalytic active sites. But in our work, even a thin layer of gold (12 nm) was coated on $\mathrm{Si}$ (111) substrate, but after the deposition no metal catalyst or any type of impurity was detected from the tips of the grown $\mathrm{ZnO}$ nanowires, as confirmed by the SEM and TEM observations. Therefore, we suggest that the growth mechanism of the product can be understood on the basis of the VS growth mechanism and small Au particles do not serve as catalysts in our case, but they simply offer favorable nucleation sites for nanowires growth. The Au thin film on $\mathrm{Si}$ substrates was expected to form nanosized $\mathrm{Au}-\mathrm{Si}$ alloy droplets as the eutectic point of $\mathrm{Au}-\mathrm{Si}$ binary system is about $363^{\circ} \mathrm{C}[39]$ on the basis of their phase diagram. After the temperature rised above $800^{\circ} \mathrm{C}$, active carbon and $\mathrm{ZnO}$ in the source materials begin to react with each other and produce $\mathrm{Zn}$ and/or $\mathrm{ZnO}_{x}$ vapor and then the $\mathrm{Zn}$ and/or $\mathrm{ZnO}_{x}$ and $\mathrm{Mg}$ vapors were transferred to the low temperature area and absorbed onto the $\mathrm{Au}-\mathrm{Si}$ alloy droplets. Then solid $\mathrm{ZnO}$ will precipitate from droplet in the form of nanowires when $\mathrm{ZnO}$ reach the supersaturating state. Meanwhile, $\mathrm{Mg}$ was doped into the $\mathrm{ZnO}$ particles through the process of $\mathrm{Mg}$ substituting of $\mathrm{Zn}$ atom in $\mathrm{ZnO}$. Continuous feeding of the reactants sustains the thickness of $\mathrm{ZnO}$ over the gold particles and gold lies beneath at the base of the formed $\mathrm{ZnO}$ nanowires [40]. Therefore, no sign of $\mathrm{Au}$ particles was observed from the tips of as-grown nanowires.

\section{Conclusion}

In summary, high-quality $\mathrm{ZnO}$ nanowires doped with $\mathrm{Mg}$ have been synthesized on Au-coated Si (111) substrates using CVD method at $850^{\circ} \mathrm{C}$. According to the results of EDX analysis, the compositions of the products are $\mathrm{Mg}$-doped $\mathrm{ZnO}$ without impurity, and $\mathrm{Mg}$ doping has not change the wurtzite structure of $\mathrm{ZnO}$ because of its small content. Most of the nanowires have diameters ranging from 50 to $80 \mathrm{~nm}$ and lengths up to hundreds of micrometres. Detailed structural characterizations indicate that the synthesized nanowires are single-crystalline and grow along the [0001] direction in preference, indicating that introduction of divalent $\mathrm{Mg}$ ion in the $\mathrm{ZnO}$ lattice did not affect the growth direction. The growth mechanism of $\mathrm{ZnO}$ nanowires can be explained by a VS growth model, and the as-deposited $\mathrm{Au}$ particles act as nucleation sites. 


\section{Acknowledgments}

The authors are grateful for the financial support of the Key Research Program of the National Natural Science Foundation of China (No. 90301002 and No. 90201025).

\section{References}

[1] B. Tian, X. Zheng, T.J. Kempa, Y. Fang, N. Yu, G. Yu, J. Huang, C.M. Lieber, Nature 449, 885 (2007).

[2] J.B. Shen, H.Z. Zhuang, D.X. Wang, C.S. Xue, H. Liu, Cryst. Growth Des. 9, 2187 (2009)

[3] L. Feng, A. Liu, Y. Ma, M. Liu, B. Man, Acta Phys. Pol. A 117, 257 (2010).

[4] W. Zaleszczyk, K. Fronc, E. Przezdziecka, E. Janik, A. Presz, M. Czapkiewicz, J. Wrobel, W. Paszkowicz, L. Klopotowski, G. Karczewski, T. Wojtowicz, Acta Phys. Pol. A 114, 1451 (2008).

[5] W. Lee, M.C. Jeong, J.M. Myoung, Appl. Phys. Lett. 85, 6167 (2004).

[6] S.W. Jung, W.I. Park, G.C. Yi, M. Kim, Adv. Mater. 15, 1358 (2003).

[7] Y.L. Seu, L. Pang, Y.L. Chia, Y.T. Tseung, J.H. Chorng, J. Phys. D, Appl. Phys. 37, 2274 (2004).

[8] J.S. Jie, G.Z. Wang, X.H. Han, Q.X. Yu, Y. Liao, G.P. Li, J.G. Hou, Chem. Phys. Lett. 387, 466 (2004).

[9] M. Yan, H.T. Zhang, E.J. Widjaja, R.P.H. Chang, J. Appl. Phys. 94, 5240 (2003).

[10] H.S. Chen, J.J. Qi, Y.H. Huang, Q.L. Liao, Y. Zhang, Acta Phys. Chim. Sin. 23, 55 (2007).

[11] K. Gas, K. Fronc, P. Dziawa, W. Knoff, T. Wojciechowski, W. Zaleszczyk, A. Baranowska-Korczyc, J.F. Morhange, W. Paszkowicz, D. Elbaum, G. Karczewski, T. Wojtowicz, W. Szuszkiewicz, Acta Phys. Pol. A 116, 868 (2009).

[12] G. Wang, Z.Z. Ye, H.P. He, H.P. Tang, J.S. Li, J. Phys. D, Appl. Phys. 40, 5287 (2007).

[13] B.K. Sonawane, M.P. Bhole, D.S. Patil, Opt. Quant. Electron. 41, 17 (2009).

[14] A. Rahm, T. Nobis, M. Lorenz, G. Zimmermann, N. Boukos, A. Travlos, M. Grundmann, Adv. Solid State Phys. 46, 113 (2008).

[15] M. Lorenz, E.M. Kaidashev, A. Rahm, T. Nobis, J. Lenzner, G. Wagner, D. Spemann, H. Hochmuth, M. Grundmann, Appl. Phys. Lett. 86, 143113 (2005).

[16] C. Czekalla, J. Guinard, C. Hanisch, B.Q. Cao, E.M. Kaidashev, N. Boukos, A. Travlos, J. Renard, B. Gayral, D.L. Dang, M. Lorenz, M. Grundmann, Nanotechnology 19, 115202 (2008).

[17] R. Kling, C. Kirchner, T. Gruber, F. Reuss, A. Waag, Nanotechnology 15, 1043 (2004).
[18] A.L. Yang, H.Y. Wei, X.L. Liu, H.P. Song, G.L. Zheng, Y. Guo, C.M. Jiao, S.Y. Yang, Q.S. Zhu, Z.G. Wang, J. Cryst. Growth 311, 278 (2009).

[19] Y.Z. Zhang, J.G. Lu, Z.Z. Ye, Y.J. Zeng, L.P. Zhu, J.Y. Huang, J. Phys. D, Appl. Phys. 40, 3490 (2007).

[20] H.C. Hsu, C.Y. Wu, H.M. Cheng, W.F. Hsieh, Appl. Phys. Lett. 89, 013101 (2006).

[21] M. Zhi, L.P. Zhu, Z.Z. Ye, F. Wang, B. Zhao, J. Phys. Chem. B 109, 23930 (2005).

[22] H. Pan, Y. Zhu, H. Sun, Y. Feng, C. Sow, J. Lin, Nanotechnology 17, 5096 (2006).

[23] H.P. Tang, H.P. He, L.P. Zhu, Z.Z. Ye, M. Zhi, F. Yang, B. Zhao, J. Phys. D, Appl. Phys. 39, 3764 (2006).

[24] C.J. Pan, H.C. Hsu, H.M. Cheng, C.Y. Wu, W.F. Hsieh, J. Solid State Chem. 180, 1188 (2007).

[25] Q. Wei, M.K. Li, Z. Yang, L. Cao, W. Zang, H.W. Liang, Acta Phys. Chim. Sin. 24, 793 (2008).

[26] X.C. Wu, J.M. Hong, Z.J. Han, Y.R. Tao, Chem. Phys. Lett. 373, 28 (2003).

[27] J.S. Lee, Y.K. Byeun, S.H. Lee, S.C. Choi, J. Alloys Comp. 456, 257 (2008).

[28] Y.C. Lin, W.T. Lin, Nanotechnology 16, 1648 (2005).

[29] F. Wang, G.Q. Jin, X.Y. Guo, J. Phys. Chem. B 110, 14546 (2006).

[30] R. Yousefi, B. Kamaluddin, Appl Surf. Sci. 256, 329 (2009).

[31] J. Wang, H.Z. Zhuang, J.L. Li, P. Xu, Acta Phys. Chim. Sin. 26, 2840 (2010).

[32] D. Qiu, H. Wu, N. Chen, Chin. Phys. Lett. 20, 582 (2003).

[33] M. Yin, Y. Gu, I.L. Kuskovsky, T. Andelman, Y. Zhu, G.F. Neumark, S. O'Brien, J. Am. Chem. Soc. 126, 6206 (2004).

[34] Y. Zhang, X. Song, J. Zheng, H. Liu, X. Li, L. You, Nanotechnology 17, 1916 (2006).

[35] K. Vanheusden, C.H. Seager, W.L. Warren, D.R. Tallant, J.A. Voigt, Appl. Phys. Lett. 68, 403 (1996).

[36] Y.W. Heo, D.P. Norton, S.J. Pearton, J. Appl. Phys. 98, $073502(2005)$

[37] B. Lin, Z. Fu, Y. Jia, Appl. Phys. Lett. 79, 943 (2001).

[38] I. Shalish, H. Temkin, V. Narayanamurti, Phys. Rev. B 69, 245401 (2004).

[39] C.Y. Lee, T.Y. Tseng, S.Y. Li, P. Lin, Tamkang J. Sci. Eng. 6, 127 (2003).

[40] D. Zhao, C. Andreazza, P. Andreazza, J. Ma, Y. Liu, D. Shen, Chem. Phys. Lett. 399, 522 (2004). 